\title{
The application of virtual reality technology to testing resistance to motion sickness
}

\author{
Galina Ya. Menshikova, Artem I. Kovalev, \\ Oxana A. Klimova, Valentina V. Barabanschikova \\ Faculty of Psychology, Lomonosov Moscow State University, Moscow, Russia \\ * Corresponding author. E-mail:
}

Background. Prolonged exposure to moving images in virtual reality systems can cause virtual reality induced motion sickness (VIMS). The ability to resist motion sickness may be associated with the level of vestibular function development. Objective. The aim of the present research is to study the oculomotor characteristics of individuals whose observation of moving virtual environments causes the VIMS effect. We hypothesized that people who have a robust vestibular function as a result of their professional activity, are less susceptible to VIMS than people who have no such professional abilities. The differences in people's abilities to resist the effects of the virtual environment may be revealed in the oculomotor characteristics registered during their interaction with a virtual environment.

Design. Figure skaters, football players, wushu fighters, and non-trained people were tested. The CAVE virtual reality system was used to initiate the VIMS effect. Three virtual scenes were constructed consisting of many bright balls moving as a whole around the observer. The scenes differed in the width of the visual field; all balls subtended either $45^{\circ}, 90^{\circ}$ or $180^{\circ}$.

Results. The results showed more active eye movements for athletes compared to non-trained people, i.e. an increase in blink, fixation, and saccade counts. A decrease in saccadic amplitudes was revealed for figure skaters. These characteristics were considered specific indicators of the athletes' ability to resist motion sickness.

Conclusions. It was found that the strength of the VIMS effect increased with the increasing width of the visual field. The effectiveness of virtual reality and eye-tracking technologies to test the VIMS effect was demonstrated.

Keywords: virtual reality technology, motion sickness, vestibular dysfunction, vection illusion, eye movement characteristics, professional abilities of athletes 


\section{Introduction}

During the last decade, virtual reality technologies became a common method used in various psychological studies. The advantages and challenges of applying these systems in experimental psychology, organizational psychology, and sports psychology have been thoroughly described and analyzed (Zinchenko, Menshikova, Bayakovskiy, Chernorizov \& Voiskounsky, 2010). The perspective for using these technologies has also been shown to play a profound role at diverse levels of innovative learning and teaching, including professional education.

Virtual reality technology is a system of visualization tools, which includes special virtual environment devices (CAVE-systems, systems of augmented reality, HMD helmets, spherical displays), as well as simpler devices such as widescreen projection 3D-displays, 3D-theaters, and virtual reality goggles. Even in the first stages of using these technologies for the development of different skills (mostly in training the spatial abilities of pilots and astronauts), negative symptoms were found, which included vertigo, nausea, spatial disorientation, and problems with balance and movement execution. Moreover, many observers noted that they had a strong impression of having moved their bodies during the interaction with virtual environment, although objectively their bodies remained stationary (Hettinger, 2002). This phenomenon has been called the self-motion illusion, or the vection illusion.

The above-mentioned negative symptoms were initially attributed to technical flaws in the virtual reality technologies themselves (Biocca, 1992). However, it has been shown that the improvement of technical characteristics (higher video resolution, and more accurate tracking and optical systems) leads to increased symptoms: for example, the latency of their appearance is significantly reduced (Bailey, Denis, Goldsmith, Hall \& Sherwood, 1994).

The complex of negative symptoms which appear in virtual environments, was initially associated with motion sickness, which occurs in the natural environment in people who travel on ships or aircraft. It was suggested that motion sickness appears because of the conflict between the sensory signals from vestibular and visual systems (Reason, 1978). For example, a person standing in a ship cabin sees the stationary surroundings of the cabin (no sense of body movement through the visual signals), while he/she perceives body movement through vestibular signals. However, later on, to describe feelings of discomfort arising from interaction with virtual reality systems, new terms were proposed, which reflected new symptoms which can be compared with those caused by commonly used devices such as centrifuges. These terms frequently correspond to the type of virtual reality device: "simulator sickness" from aviation, car, or motorcycle simulators (Kellogg, Kennedy \& Graybiel, 1964); “cyber-sickness" from videogames on big screens (Keshavarz \& Berti, 2014); and "cinema-sickness" from 3D-theaters (Griffin, 2012).

Other studies showed a stronger influence of the virtual environment: of 1102 participants in one experiment, $142(12.9 \%)$ stopped the experiment, and 960 (87.1\%) reported a high level of discomfort (Sharples, Cobb, Moody \& Wilson, 2008). The symptoms described were so robust, that in 2005 the International Organization for Standardization (ISO) compelled the manufacturers of widescreen 
displays to conduct special tests of the potential for inducing vection illusion in users before the product could be put on the market.

To solve these problems in the use of virtual reality devices, it is necessary to both assess their impact, and to identify the individual characteristics of the people who are able to resist their impact. In previous studies, both objective and subjective procedures were developed to find appropriate measurements. Large individual differences in discomfort symptoms have been revealed, so methods of subjective assessment became the most common. One subjective method is the generally accepted Simulator Sickness Questionnaire (SSQ). It was developed by R.S. Kennedy and his colleagues (Kennedy, Lane, Kevin, Berbaum \& Lilienthal, 1993) on the basis of the Pensacola motion sickness questionnaire (MSQ). The latter was created by NASA to assess the condition of prospective astronauts after their training in centrifuge and swimming pool weightlessness simulators (Kellogg, Kennedy \& Graybiel, 1964). Three results were found-nausea, oculomotor reactions, and disorientation-which were used to calculate a total score indicating the severity of the simulator sickness.

Using the MSQ and SSQ measures, studies showed that simulator sickness occurred in only some of the study subjects, and its intensity changed depending on the level of subjects' adaptation to the virtual environment. This data allowed researchers to suggest that different people can resist the impact of virtual reality devices by relying on special skills they have obtained in their professional activities (McLeod, Reed, Gilson \& Glennerster, 2008). This suggestion has been confirmed in experiments (Howarth \& Costello, 1997) which tested the negative impact of helmets constructed by different manufacturers. The SSQ results were estimated for participants who played a shooter computer game for an hour. It appeared that their simulator sickness severity depended more on skills of interaction with the virtual games than on helmet's technical specifications. Specifically, those participants who had more experience playing computer games, especially car and aviation simulators, scored lower points on the SSQ scale.

The influence of user mobility on the severity of the simulator sickness was also demonstrated in studies of user-control in a virtual environment (Stanney, Hale, Nahmens, \& Kennedy, 2003). It was shown that in situations where participants were allowed to actively move around in a virtual environment, they had lower rates of discomfort: only a few subjects complained of simulator disorders. The successful participants were found to have had a great deal of past experience interacting with computer games, so it took less time for them to adapt to user control activities in the virtual environment.

However, the MSQ and SSQ measurements have some disadvantages: first, the estimates are based on memories of past virtual events; second, SSQ measurements do not allow for testing the process by which the individual develops a sense of discomfort. So, it is necessary to work out special methods for assessing the severity of simulator sickness which would avoid these shortcomings. These methods should include both objective and subjective measures, which both reflect the person's interaction with virtual reality systems. Attempts to use vegetative reactions as objective measures were made but were unsuccessful, because these reactions have been considered to reflect only unspecified stress states under the influence of the virtual environment (Harm, Schlegel, 2012). 
Eye movement characteristics were also considered to be objective measures of the person's behavior during the observation of virtual events. Oculomotor activity has long been studied in the context of explaining simulator sickness. It was proposed that proprioceptive signals of the eye muscles were one of the reasons for the occurrence of the vection illusion where you had a moving virtual environment and a stationary observer (Ebenholtz, Cohen \& Linder, 1994). Eye movements were considered to be indicators of vestibular dysfunction which leads to the appearance of the vection illusion. Moreover, it was suggested that the vestibular-ocular reflex plays an important role in the appearance of the observer's illusory movements in the virtual environment (Smit, 2005; Authie \& Mestre, 2011).

\section{Method}

The aim of the present research is to study oculomotor characteristics as indicators of a person's ability to resist motion sickness symptoms. The problem of the impact of virtual reality systems on the person's behavior mains poorly understood despite its high significance. We hypothesize that people with a vestibular system developed as a result of their professional activity, are less susceptible to simulator sickness compared with people who have no such professional abilities. The differences in a person's ability to resist the effects of the virtual environment may be revealed in the oculomotor characteristics registered during his/her interaction with virtual environment.

\section{Participants}

The ability to resist motion sickness induced by virtual reality devices was tested in experimental (90 observers: 29 females and 61 males) and control (20 observers: 11 females and 9 males) groups. The experimental group consisted of professional athletes in three sports - figure skating, wushu fighting, and football. In order to assess how athletes adapt to the virtual reality environment, we tested 30 figure skaters (18 females and 12 males, age range 15-24) with a high level of professional skill-21 figure skaters had a "master of sport" rank and 9 "candidate for master of sport" rank; 30 football players (30 males, age range 15-20) also with a high level of professional skill-7 football players had "master of sport" and 23 "candidate for master of sport" rank; and 30 wushu fighters (11 females and 19 males, age range 16-21) with a high level of professional skill -20 of them had "master of sport" rank and 10 "candidate for master of sport" rank. As a control group, we used 20 students from Lomonosov MSU (9 males and 11 females, age range 18-24), who were not professional athletes. All participants had normal or corrected-to-normal vision and had no organic lesions of the vestibular system, or brain injury.

The reason for choosing the above-mentioned athletes was the following. Figure skaters, wushu fighters, and football players are considered highly professional elite athletes (Hutter, Oldenhof-Veldman \& Oudejans, 2015). It was shown that these athletes had been trained since their childhood to perform a variety of complex elements (rotations, reversals, etc.), so they had well-developed vestibular systems. Typical exercises in figure skating include many elements with mostly acyclic 
movements. The large variety of movement forms involved lead to the development of different types of locomotor coordination (Absalyamova, Belyaeva \& Zhgun, (1992). Mastering this sport has a great impact not only on the locomotor system but also on the sensory system functions (Mishin, 1985).

For wushu fighters the most important task is to sustain a posture and coordinate precise movements. Like figure skaters, wushu fighters have to execute a program consisting of multiple consecutive locomotion elements. Pre-defined movement rhythm and limited space, along with the large variety of complex elements, require a highly developed vestibular function. However, the professional activities of wushu fighters differ from the activities of figure skaters with respect to the need for movement speed and accuracy (Volkov, 2002).

Another sport which involves a high degree of dynamic abilities is football. Football players should be able to control the game situation on a large area of a football field, so central and periphery visual signals are an important part of their vestibular system development. These activities are similar to figure-skating activities, where athletes need to control their central and peripheral visual perspective, and resist the narrowing of the field of vision during the execution of a specific element (McLeod et al., 2008).

According to our initial hypothesis, the figure skaters were expected to demonstrate a higher ability to resist motion sickness symptoms than the other groups of athletes. Of the latter, wushu fighters were thought to be more successful in resisting motion sickness than football players. These assumptions were formulated on the basis of an analysis of athletes' professional activity. Their specific characteristics (main goals, means, and desired results) are presented in Table 1.

Table 1. Athletes' activity during competition

\begin{tabular}{|c|c|c|c|}
\hline & Activity goals & Activity means & Desired results \\
\hline $\begin{array}{l}\text { Figure } \\
\text { skaters }\end{array}$ & $\begin{array}{l}\text { Artistry } \\
\text { Program complexity } \\
\text { Movement precision } \\
\text { Movement elements } \\
\text { Accuracy }\end{array}$ & $\begin{array}{l}\text { Artistic image } \\
\text { Vestibular function } \\
\text { Coordination } \\
\text { Balance } \\
\text { Reaction speed }\end{array}$ & $\begin{array}{l}\text { Demonstration of professional } \\
\text { skills during competition } \\
\text { Precise execution of the elements } \\
\text { Victory in the competition }\end{array}$ \\
\hline $\begin{array}{l}\text { Wushu } \\
\text { fighters }\end{array}$ & $\begin{array}{l}\text { Movement precision } \\
\text { Movement elements } \\
\text { Accuracy }\end{array}$ & $\begin{array}{l}\text { Vestibular function } \\
\text { Coordination } \\
\text { Balance } \\
\text { Reaction speed }\end{array}$ & $\begin{array}{l}\text { Demonstration of professional } \\
\text { skills during competition } \\
\text { Precise execution of the elements } \\
\text { Victory in the competition }\end{array}$ \\
\hline $\begin{array}{l}\text { Football } \\
\text { players }\end{array}$ & $\begin{array}{l}\text { Execute movement se- } \\
\text { quences, leading to the } \\
\text { team's victory, directly } \\
\text { and indirectly }\end{array}$ & $\begin{array}{l}\text { Coordination } \\
\text { Vestibular function } \\
\text { Reaction speed } \\
\text { Visual control of wide } \\
\text { field of vision }\end{array}$ & $\begin{array}{l}\text { It depends on the athlete's role: } \\
\text { for the goalkeeper it is the } \\
\text { number of goals conceded; for } \\
\text { the forward, the number of goals } \\
\text { scored }\end{array}$ \\
\hline
\end{tabular}

It is necessary to note that our analysis was focused on the athlete's performance during competition, since that's when his/her professional skills are manifest most clearly. As seen in Table 1, the number of professional tasks for football players is 
limited. This may be understood as due to the fact that a narrower range of skills is required if one is training specifically to become a professional goalkeeper, a fullback, or a forward. On the contrary, wushu fighters and figure skaters have to possess a much greater range of skills, including artistry and mastering the complexity of the program.

Figure skating is the hardest sport in this regard, because it combines these requirements with a need for high speed of execution and precise coordination of athlete's body parts. So a well-developed vestibular system may be considered the most important factor for effective execution of the necessary elements - rotations, acrobatic elements, jumping, etc. Since the vestibular system is such a significant quality for a professional figure skater, it should be developed during very early professional specialization (at about 4-5 years of age), and should be tested throughout the period of professional growth. Wushu fighters possess a similar set of skills; however, due to the smaller percentage of complex rotations required, the role of the "vestibular" factor may be not as significant for their professional training.

\section{Stimuli}

To simulate motion sickness symptoms, special virtual environments were constructed. They consisted of a set of bright blue balls (total =256), which spun as a whole around the observer. The average speed of the balls' rotation was $24 \%$ s. To vary the impact of the virtual reality environments, three different virtual scenes were constructed which differed in the width of their visual fields. It was shown that the wider the visual field the observer used, the stronger was the simulator sickness (Menshikova, Kovalev, Klimova, Chernorizov, \& Leonov, 2014). Thus, changes in the width of the viewing angle could gradually alter the severity of simulator sickness symptoms. Virtual scenes with three conditions were designed: in the first condition, all balls subtended $45^{\circ}$ (the central part of the frontal screen); in the second, the balls subtended $90^{\circ}$ (the whole frontal screen); in the third, they subtended $180^{\circ}$ (the frontal and two side screens). The balls' diameters were $0.1^{\circ}, 0.3^{\circ}$ and $0.5^{\circ}$ in the first, second, and third conditions, respectively.

\section{Apparatus}

The CAVE virtual reality system was used for the stimulation presentation (Fig. 1). The device had four large flat screens (Barco ISpace 4), which were connected into one cube consisting of three walls and a floor. The length of screen side was about 2.5 meters. Shutter eye glasses CrystalEyes 3 Stereographics were used. The projection system was based on BarcoReality 909. The projector's matrix resolution was $1400 \times 1050$ with $100 \mathrm{~Hz}$ update frequency. The tracking system was produced by ArtTrack2. VirTools 4.0 was used for software development. It supported DX9/ GL2, HAVOK, particle systems, and shaders. The laboratory room was darkened. There were no any light sources except the CAVE systems projectors. The luminance range in stimulus scene was $1: 230$. The maximum luminance was $5.5 \mathrm{~cd} / \mathrm{m}^{2}$, the minimum $0.02 \mathrm{~cd} / \mathrm{m}^{2}$.

Eye movements were registered with SMI Eyetracking glasses 2.0, which have a resolution of $0.5^{\circ}$ and a refresh rate of $60 \mathrm{~Hz}$. 


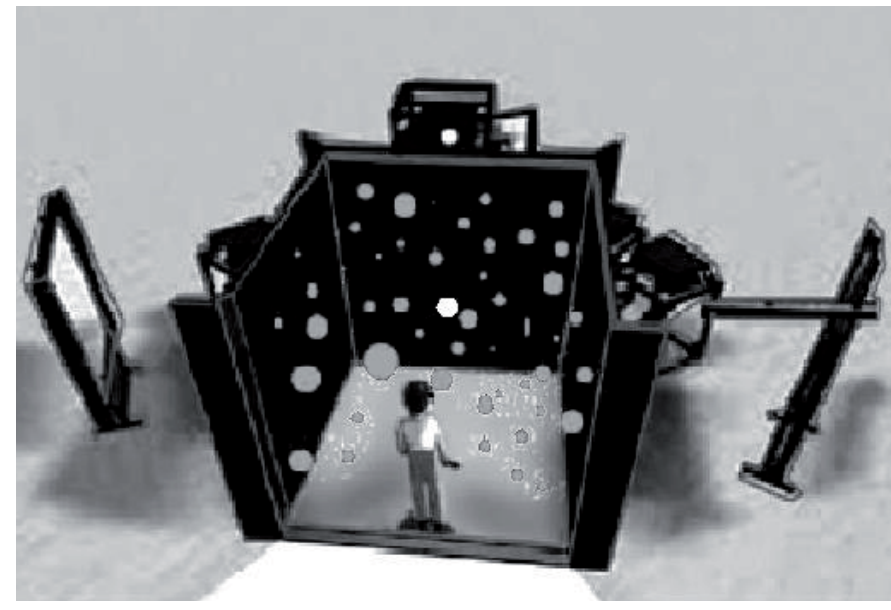

Figure 1. The main view of the CAVE system

\section{Procedure and plan}

The participant stood motionless in front of the central screen at a distance of $2.5 \mathrm{~m}$ observing the rotation of virtual balls around her/him. The rotation was carried out along the curved trajectory and lasted for two minutes for each condition. There was a fixation point in the center of the frontal screen (size: $0.5^{\circ}$; red in color). The whole experiment consisted of three presentations differed in the width of visual field (three conditions). The order of presentations was randomized. At the end of each presentation the participant completed the modified version of the SSQ questionnaire and then had a rest of 5 minutes. The entire experiment lasted approximately 25 minutes. At the end of the experiment, the participant was asked to report the feelings he experienced during interaction with the virtual environment.

\section{Measurements}

Objective and subjective measurements were used to evaluate the severity of the participants' motion sickness . Different eye movement characteristics (number of fixations, blinks, and saccades, saccade amplitudes) were used as objective measures, along with the ranking of the SSQ questionnaires as subjective measures. The data obtained was analyzed with SPSS 21.

\section{Results}

The data was analyzed using a two-way analysis of variance (ANOVA). The multidimensional tests showed statistically significant impacts of the factors "Number of conditions" $(\mathrm{F}(16)=77.86, \mathrm{p}=0.001)$ and "Affiliation to a professional group" $(\mathrm{F}(24)=2.54, \mathrm{p}=0.001)$ on the variables. Furthermore, the interaction between factors also reached a level of significance $(\mathrm{F}(48)=2.47, \mathrm{p}=0.001)$. Thus, we showed that levels of oculomotor characteristics and questionnaire scores vary according to "professional group" affiliation. All conditions differed significantly according to oculomotor characteristics and to total questionnaire scores, as was revealed by the 
intergroup contrasts method: "blink count" $(\mathrm{F}(3)=6.62, \mathrm{p}<0.01)$, "fixation count" $(\mathrm{F}(3)=4.15, \mathrm{p}<0.01)$, "saccade count" $(\mathrm{F}(3)=6.05, \mathrm{p}<0.01)$, "saccade amplitude" $(\mathrm{F}(3)=16.39, \mathrm{p}<0.01)$, "Total score" $(\mathrm{F}(3)=18.18, \mathrm{p}<0.01)$.

The data on the SSQ questionnaires was summarized separately for the various conditions and professional groups. The mean values of SSQ total scores for the experimental (figure skaters, wushu fighters, football players) and control groups are shown in Fig. 2 for the first, second, and third viewing conditions $\left(45^{\circ}=\right.$ black columns, $90^{\circ}=$ gray columns, and $180^{\circ}=$ striped columns). According to the schedule, SSQ score values significantly differ $(F(1)=57.36, p<0.001)$ between conditions for any group except the skaters group. For this group the increase of the field of vision (from $90^{\circ}$ up to $180^{\circ}$ ) was not accompanied by an increase in total score. This result agrees with the skaters' self-reports: they felt no symptoms of strong discomfort during the observation of any moving virtual environments. On the contrary, all the other groups (wushu fighters, football players, and the control group) had twice increased their SSQ Total scores (up to 800 points) when the field of vision was changed from $90^{\circ}$ to $180^{\circ}$. In self-reports they described their feelings as "dizziness with open eyes" and "nausea," and also noted increased difficulties in maintaining their gaze. Some participants complained they could hardly wait until the end of the experiment.

Data on oculomotor characteristics (blink, fixation, and saccade counts; saccade amplitudes) were also analyzed separately for the three conditions and professional groups. It was shown that all viewing conditions differed significantly $(\mathrm{F}(16)=77.87, \mathrm{p}<0.001)$ according to the mentioned eye movement characteristics. The mean number of blinks, fixations, and saccades per minute for all three conditions (first $=45^{\circ}$, second $=90^{\circ}$, and third $=180^{\circ}$, respectively) and for all groups are shown in Fig. 3. Their analysis shows that the mean values of oculomotor parameters differ insignificantly between the subject groups for the first $(\mathrm{t}(29)=0.81$,

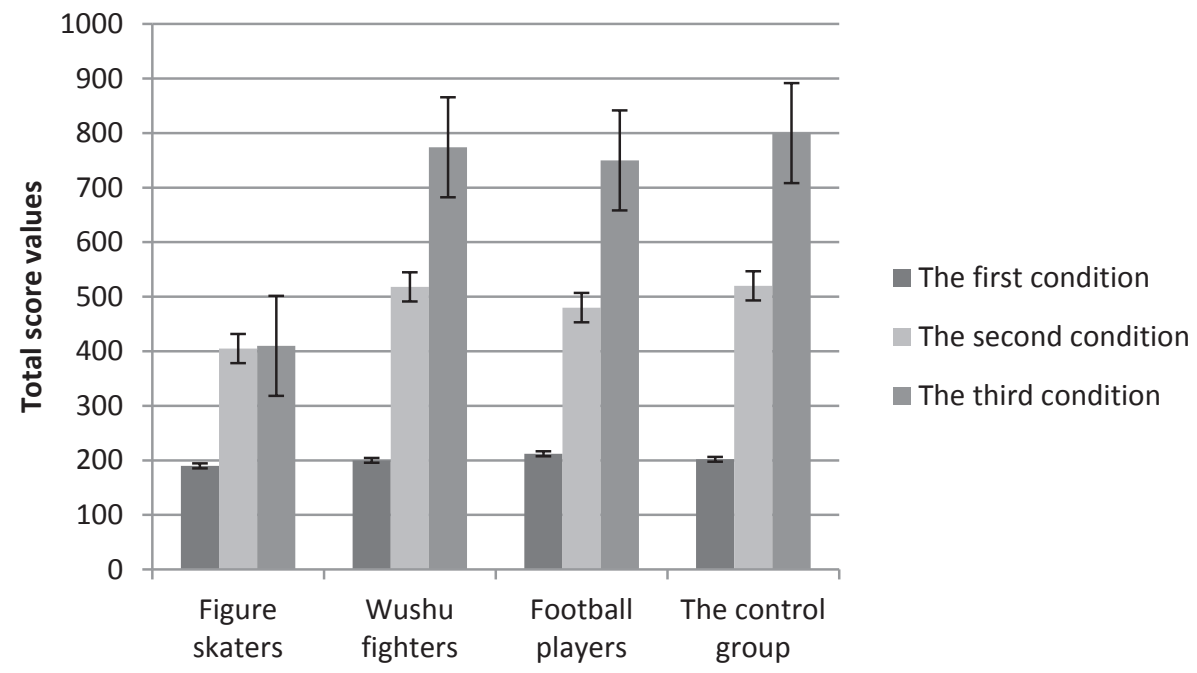

Figure 2. Mean values of SSQ Total scores for the experimental (figure skaters, wushu fighters, football players) and control groups in the first, second, and third viewing conditions 


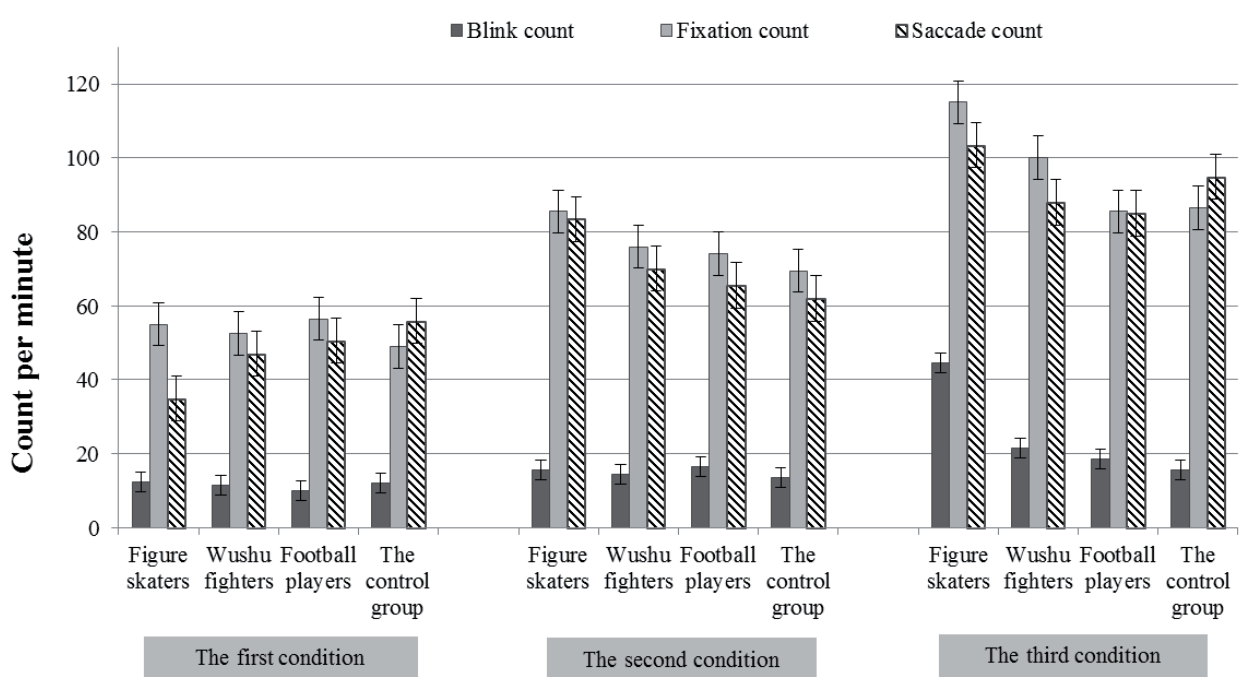

Figure 3. Mean values of blink, fixation, and saccade counts for the experimental (figure skaters, wushu fighters, football players) and control groups in the first, second, and third viewing conditions

$\mathrm{p}>0.05)$ and second conditions $(\mathrm{t}(29)=0.77, \mathrm{p}<0.05)$. However, the third condition is significantly differentiated from the others in respect to oculomotor parameters: blink, fixation, and saccade counts increase in comparison with the first and second conditions. In particular, figure skaters have significantly greater oculomotor characteristics for the third condition $(\mathrm{t}(29)=3.34, \mathrm{p}<0.01)$. This result is consistent with the SSQ Total scores. Mean values of saccade amplitudes for all three conditions (first $=45^{\circ}$, second $=90^{\circ}$ and third $=180^{\circ}$, respectively) and for all groups are shown in Figure 4. The analysis of oculomotor characteristics of the experimental and control groups has been done for each condition separately.

In the first condition, both athletes and participants from the control group have approximately the same number of blinks (23), fixations (106), and saccades (94) counts per minute. The saccade amplitudes also vary only slightly, and their average value is about $7.3^{\circ}$. The SSQ total score is not very high either: its average value is about 201 for all participants (Fig. 2). This data is consistent with the selfreports by all participants which we received after their observation of the moving virtual environment in the first condition: they did not mention any feelings of discomfort.

The second condition differs from the first in that there was a substantial increase in all oculomotor characteristics in all subject groups. However, it should be noted that for figure skaters, changes in eye movements differ from eye movement changes in other participants. For example, their saccade amplitudes increase on average by $12 \%$ whereas for other participants it increases by $40 \%$. As for fixation, blink, and saccade counts, their values increase more in the second condition than in the first. Specific changes in the skaters' eye movements may be explained by their ability to resist the moving environment due to their professional training. Furthermore, subjective levels of discomfort evaluated on the basis of the self-re- 


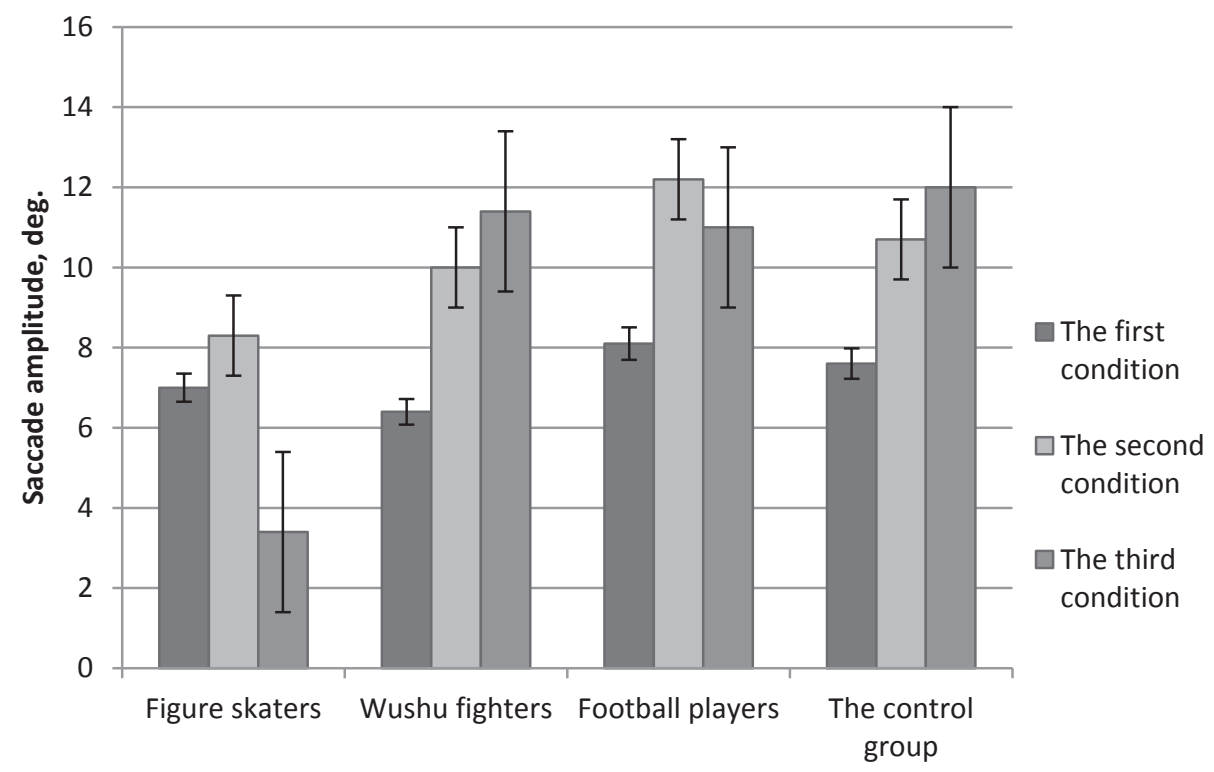

Figure 4. Mean values of saccade amplitudes for the experimental (figure skaters, wushu fighters, football players) and the control group in the first, second and third viewing conditions

ports and questionnaire scores were lower for the figure skaters than in the other participants.

Analysis of the third condition showed the highest results in almost all oculomotor characteristics for figure skaters. It should be noted that athletes of other groups (wushu fighters, football players) did not differ from untrained participants of the control group in respect to their oculomotor characteristics and SSQ scores.

\section{Discussion}

A figure skater's ability to successfully resist simulator sickness may be explained by his/her better developed vestibular function, which is considered the most important professional quality for this sport. Certain changes in oculomotor characteristics, in our opinion, are related to special aspects of figure skaters' athletic activity, which are actively developed from the early stages of professional specialization. Multiple accelerations and slowdowns, bows and rotations, and mastering the difficulties of maintaining balance on a limited supporting space, actively increase the ability of the body to evaluate its position and locomotion precisely, and thus lead to the development of the skater's vestibular function. At the same time many other functions are being developed (i.e., the so-called "feel of the ice")-muscular, joint and tactile sensitivities, eye estimation precision, differentiation of acoustic sensations, and the ability to integrate signals of different sensory systems during the execution of complex program elements (Chaikovskaya, 2003).

A number of studies have been devoted to highlighting vestibular habituation in populations who perform such complex program elements. In particular, they showed changes in the slow phase of vestibular ocular reflexes (VOR). In ballet 
dancers (Tschiassny, 1957) the VOR slow phase velocity is lower in comparison to non-trained participants. (Osterhammel et al. 1968). The VOR of gymnasts is characterized by a $15 \%$ shortening of slow phase and by a $25 \%$ decrease in saccadic amplitudes (Quarck et al., 1998). Among fighter pilots, the duration of the post-rotational nystagmus is also shorter (Aschan, 1954) than among civil aviation pilots.

We suggest that the reason for the differences in the characteristic eye movements of the figure skaters in our experiment is a change in their optokinetic nystagmus (OKN). OKN is similar to VOR in that OKN characteristics, such as a decrease in slow phase, may also be linked with habituation to their vestibular load. The fact that figure skaters have the lowest SSQ scores coheres with the habituation hypothesis since vestibular habituation seems to be accompanied by reduced motion sickness (MS). Thus, after a month of regular navigation, candidates for future maritime service become less sensitive to seasickness and show VOR habituation (Shupak et al. 1990). Repeated stimulation of the vestibular system as part of cosmonaut vestibular training also induced a decrease in MS (Clement et al. 2001). Repetitive vestibular stimulation can therefore cause changes in VOR and OKN, and at the same time a reduction in sensitivity to MS in virtual reality.

The analysis of the data on the football players revealed that negative symptoms (vertigo and nausea) appeared for the third condition (visual field of $180^{\circ}$ ). Along with the emergence of these symptoms, there was a lack of change in fixation and blink counts when compared with the first, second, and third conditions, which may be closely associated with their professional ability to control a whole visual field during the game. According to other authors, the ability to pay attention to objects located at the periphery of the visual field should be considered as one of the main professional qualities of football players (Williams, 2002). It was shown (Vaeyens, et al., 2007) that when the number of players in the environment increases, players change from exhibiting a low visual search rate with prolonged fixations, to a higher visual search rate of shorter duration. Evidently football players have started to realize their professional gaze behavior, which leads to an increase in the presence effect, and in the end to the higher vection strength. This assumption is in agreement with findings of a positive correlation between vection strength, motion sickness, and the presence effect.

\section{Conclusion}

The effectiveness of virtual reality systems for testing the professional abilities (namely the resistance to motion sickness) was demonstrated. These technologies allow researchers to initiate different kinds of vestibular function disturbances and to assess their strength in a real-time mode. Their application is effective for sportspeople of any age, especially for young athletes, who need to qualify to be selected for professional status in the early stages of their education.

A method based on eye movement characteristics can be successfully applied for testing resistance to motion sickness. Typical changes in eye movement characteristics were revealed in athletes, especially figure skaters, compared with participants not involved in professional sports. Athletes showed more active eye move- 
ments-an increase in blink, fixation, and saccade counts. The decrease in saccadic amplitudes was revealed for figure skaters. The eye movement data were consistent with Simulator Sickness Questionnaire scores.

Further research will be concentrated on the precise extraction gaze pattern, which is linked to the vection illusion, which can predict motion sickness. It is necessary likewise to clarify what exactly are the relevant stimulus parameters that increase vection. Therefore the future virtual scenes will be different in content from naturalistic visual stimuli to optokinetic drums to estimate the high-level and low-level influences on resistance to motion sickness.

Finally, in this study we did not investigate possible multi-sensory influences on motion sickness. The question we will ask in future experiments is how much visually-induced motion sickness in athletes is increased by adding other sensory modalities.

\section{Acknowledgments}

This work was supported by the Russian Foundation for Humanities (Grant no. 16-06-00312) and by the M.V. Lomonosov Moscow State University Program of Development.

\section{References}

Absalyamova, I.V., Belyaeva, A.Yu., \& Zhgun, E.V. (1992). Posobie po sinkhronnomu kataniyu na konkakh: Tochnye linii [The handbook of synchronized skating: Accurate lines]. Moscow: GTsOLIFK.

Aschan, G. (1954). Response to rotatory stimuli in fighter pilots. Acta Otolaryngologica, 116, 24-31. doi: 10.3109/00016485409130269

Authié, C.N., \& Mestre , D.R. (2011). Optokinetic nystagmus is elicited by curvilinear optic flow during high speed curve driving. Vision Research, 16, 1791-1800. doi: 10.1016/j. visres.2011.06.010

Bailey, L., Denis, J.H., Goldsmith, G., Hall, P.L., \& Sherwood, J.D. (1994). A wellbore simulator for mud-shale interaction studies. Journal of Petroleum Science and Engineering, 11, 195-211. doi: 10.1016/0920-4105(94)90040-X

Biocca, F. (1992). Will simulation sickness slow down the diffusion of Virtual Environment technology? Presence: Teleoperators Virtual Environments, 1(3), 334-343. doi: 10.1162/ pres.1992.1.3.334

Brooks, J., Goodenough, R., Crisler, M., Klein, N., Alley R., Koon, B., ... \& Wills, R. (2010). Simulator sickness during driving simulation studies. Accident Analysis \& Prevention, 42(3), 788-796. doi: 10.1016/j.aap.2009.04.013

Chaikovskaya, E.A. (2003). Figurnoe katanie [Figure skating] Moscow: Fizkultura i sport.

Clement, G., Deguine, O., Parant, M., Costes-Salon, M., Vasseur-Clausen, P., \& Pavy-LeTraon, A. (2001). Effects of cosmonaut vestibular training on vestibular function prior to spaceflight. European Journal of Applied Physiology, 85, 539-545. doi: 10.1007/s004210100494

Ebenholtz, S.M., Cohen, M.M., \& Linder, B.J. (1994). The possible role of nystagmus in motion sickness: A hypothesis. Aviation Space and Environmental Medicine, 65, 1032-1035.

Griffin, M. (2012) Handbook of human vibration. London: Academics Press.

Harm, D.L., \& Schlegel, T.T. (2012). Predicting motion sickness during parabolic flight. Autonomic Neuroscience: Basic and Clinical, 97(2), 116-121. doi: 10.1016/S1566-0702(02)00043-7 
Hettinger, L.J., Berbaum, K.S., Kennedy, R.S., Dunlap, W.P., \& Nolan, M.D. (1990). Vection and simulator sickness. Military Psychology, 2(3), 171-181. doi: 10.1207/s15327876mp0203_4

Hettinger, L.J. (2002). Illusory self-motion in virtual environments. In K.M. Stanney (Ed.), Handbook of virtual environments (pp. 471-492). Mahwah, NJ: Lawrence Erlbaum.

Howarth, P.A., \& Costello P.J. (1997). The occurrence of virtual simulation sickness symptoms when an HMD was used as a personal viewing system. Displays, 18(2), 107-116. doi: 10.1016/ S0141-9382(97)00011-5

Hutter, R.V., Oldenhof-Veldman, T.M., \& Oudejans, R.R. (2015). What trainee sport psychologists want to learn in supervision. Psychology of Sport and Exercise, 16, 101-109. doi: 10.1016/j.psychsport.2014.08.003

Jing, C.D.H. (1998). Competitive series of skills and tricks in wushu - the main way to preserve and develop Chinese wushu. Journal of Chengdu Physical Education Institute, 1, 372-384.

Kellogg, R.S., Kennedy R.S., \& Graybiel, A. (1964). Motion sickness symptomatology of labyrinthine defective and normal subjects during zero gravity maneuvers. Aerospace Medicine, 36, 315-318.

Kennedy, R.S., Hettinger, L.J., \& Lilienthal, M.G. (1990). Simulator sickness. Motion and Space Sickness, 1, 317-341. . doi: 10.1207/s15327108ijap0303_3

Kennedy, R.S., Lane, N.E., Kevin, S., Berbaum, K.S., \& Lilienthal, M.G. (1993). Simulator Sickness Questionnaire: An enhanced method for quantifying simulator sickness. The International Journal of Aviation Psychology, 3(3), 203-220.

Keshavarz, B., \& Berti, S. (2014). Integration of sensory information precedes the sensation of vection: A combined behavioral and event-related brain potential (ERP) study. Behavioural Brain Research, 259(1), 131-136. doi: 10.1016/j.bbr.2013.10.045

McCauley, M.E., \& Sharkey, T.J. (1998). Cybersickness: Perception of motion in virtual environments. Presence: Teleoperators Virtual Environments, 1(3), 311-318. doi: 10.1162/ pres.1992.1.3.311

McLeod, P., Reed, N., Gilson, S., \& Glennerster, A. (2008). How soccer players head the ball: A test of optic acceleration cancellation theory with virtual reality. Vision Research, 48(13), 1479-1487. doi: 10.1016/j.visres.2008.03.016

Menshikova, G., Kovalev, A., Klimova, O., Chernorizov, A., \& Leonov, S., (2014). Testing the vestibular function development in junior figure skaters using the eye tracking technique. Procedia - Social and Behavioral Sciences, 146(25), 252-258. doi: 10.1016/j.sbspro.2014.08.123

Mishin, A. N. (1985). Figurnoe katanie na konkakh: uchebnik dlya institutov fiz kultury [Figure skating on ice: The handbook for sport institutes]. Moscow: Fizkul'tura i sport.

Mon-Williams, M., Wann, J.P., \& Rushton, S. (1995). Design factors in stereoscopic virtual-reality displays. Journal of the Society for information Display, 3(4), 207-210. doi: 10.1889/1. 1984970

Osterhammel, P., Terkildsen, K., Zirstorf, K. (1968). Vestibular habituation in ballet dancers. Acta Otolaryngologica, 66, 221-228. doi: 10.3109/ 00016486809126289

Quarck, G., Etard, O., Darlot, C., \& Denise, P. (1998). Motion sickness susceptibility correlates with otolith- and canal-ocular reflexes. Neuroreport, 9, 2253-2256. doi:10.1097/00001756199807130-00019

Reason, J.T. (1978). Motion sickness adaptation: A neural mismatch model. Journal of the Royal Society of Medicine, 71, 819-829.

Riccio, G.E., \& Stoffregen, T.A. (1991). An ecological theory of motion sickness and postural instability. Ecological Psychology, 3(3), 195-240. doi: 10.1207/s15326969eco0303_2

Sharples, S., Cobb, S., Moody, A., \& Wilson, J. R. (2008). Virtual reality induced symptoms and effects (VRISE): Comparison of head mounted display (HMD), desktop and projection display systems. Displays, 29(2), 58-69. doi: 10.1016/j.displa.2007.09.005 
Shupak, A., Kerem, D., Gordon, C., Spitzer, O., Mendelowitz, N., \& Melamed, Y. (1990). Vestibulo-ocular reflex as a parameter of seasickness susceptibility. Annals of Otology, Rhinology, and Laryngology, 99, 131-136. doi: 10.1177/000348949009900211

Smit, K., \& Yu, M. (2005) Biologiya sensornykh sistem [Biology of sensory systems]. Moscow: Binom.

Stanney, K.M., Hale, K.S., Nahmens, I., \& Kennedy, R.S. (2003). What to expect from immersive virtual environment exposure: Influence of gender, body mass index, and past experience. Human Factors: The Journal of the Human Factors and Ergonomics Society, 45(3), 504-520. doi: 10.1518/hfes.45.3.504.27254

Timmis, A., Turner, K., \& van Paridon, K. (2014). Visual search strategies of soccer players executing a power vs. placement penalty kick. PLoS ONE, 9(12), e115179. doi:10.1371/journal. pone.0115179

Tschiassny, K. (1957). Studies concerning vestibular factors in the ballet dancer, the pigeon and the blind person. Transactions. Section on Otolaryngology American Academy of Ophthalmology and Otolaryngology journal, 61(4), 503-506.

Vaeyens, R., Lenoir, M., Philippaerts, M., \& Williams, A.M. (2007). Mechanisms underpinning successful decision making in skilled youthful soccer players: An analysis of visual search behaviors. Journal of Motor Behavior, 39, 395-408. doi: 10.3200/JMBR.39.5.395-408

Volkov, I.P. (2002). Sportivnaya psikhologiya $v$ trudakh otechestvennykh spetsialistov [Sport psychology in domestic specialists review]. Moscow: Piter.

Williams, A.M. (2000). Perceptual skill in soccer: Implications for talent identification and development. Journal of Sport Sciences, 18, 1-14. doi: 10.1080/02640410050120113

Zinchenko, Yu.P., Menshikova, G.Ya., Bayakovsky, Yu.M., Chernorizov, A.M., \& Voiskounsky, A.E. (2010). Technologies of virtual reality in the context of World-wide and Russian psychology: methodology, comparison with traditional methods, achievements and perspectives. Psychology in Russia. State of the Art, 3, 12-45. doi: 10.11621/pir.2010.0001

Original manuscript received April 29, 2016

Revised manuscript accepted October 10, 2016

First published online September 30, 2017 